\title{
Tuva Türkçesinde “yansıma söz + de-, kıl- (kın- ve kalın-)" yapısı
}

\section{İlker TOSUN1}

APA: Tosun, İ. (2019). Tuva Türkçesinde "yansıma söz + de-, kll- (kın- ve kılın-)" yapısı. RumeliDE Dil ve Edebiyat Araştırmaları Dergisi, (Ö5), 23-36. DOI: 10.29000/rumelide.606066.

\section{$\ddot{O} \mathbf{z}$}

Yansıma sözcükler, doğanın, insanların veya hayvanların çıkarmış oldukları seslerin taklit edilmesiyle oluşan sözcükler olarak tanımlanabilir. Dilbiliminde bu tür sözcüklere İng. onomatopeia, mimetic word, echo word, echoism, imitative word; Alm. lautmalerei, schallnachahmung; Osm. lafz1 taklidi, savt-ı taklidi; Rus. zvukopodrazhaniye; Tuv. öttünüg söster gibi adlar verilmektedir. Bütün dünya dillerinde yansıma sözcüklere rastlanılır. Türk dilinin tüm alanlarında da söz varlığında çok sayıda yansıma sözcüğe rastlamak mümkündür. Türk dilinde bu yansıma sözcükler kimi zaman çeşitli eklerle fiil haline getirilmektedir. Tuva Türkçesinde yansıma sözcüklere +IrA- (buzuracızırdamak); +(A)r- (dızıra- çatırdamak); +LA- (siile- şiddetle esmek); +rA- (şlıra- fişırdamak); +DA- (ıtta- ses çıkarmak); +A- (doğdura- gümbürdemek); +KIlA- (dıngıla- şakırdamak); +KAyn(daldırtkayın- hışırdayıp durmak) ve +GIr(A)- (kaygıra-, çıngırdamak) gibi ekler getirilmek suretiyle fiiller türetilmektedir. Bu sahada ayrıca yansıma sözcükler yardımcı fiiller ile birlikte de kullanılabilmektedir. Tuva Türkçesinde yansıma sözcüklerle birlikte de- ve kıl-, kın- ve kılın- gibi yardımcı fiiller kullanılmaktadır. Bu yardımcı fiiller, bir sesin aniden ortaya çıktığını göstermektedir. Tuva Türkçesi gramerlerinde "dürgen vid” (anilik görünüşü) olarak isimlendirilen bu kullanımlar için şu örnekler verilebilir: çıjırt de- "gürültü yapmak", dırbaş de- "irkilmek"; dazırt kın- "çatırdamak", dıylaş kın- "sallamak"; dırt kıl- "aniden vurmak", tok kıl- "vurmak”; karaş kılın- "görünüp kaybolmak”, kıngırt kılın- "çınlamak”. Bu çalışmada de-, kıl-, kın- ve kılın- yardımcı fiillerinin yansıma sözcüklerle olan kullanımı üzerinde durulacaktır.

Anahtar kelimeler: Yansıma, yansıma sözcükler, Tuva Türkçesi, yardımcı fiil.

\section{Structure of "onomatopetic word + de-, kzl- (kzn-, kzlin-)" in Tuvan Turkish}

\begin{abstract}
Onomatopoeia can be defined as this kind of words through the imitation of sounds from nature, animals, and humans. In linguistics, onomatopoeic words are given Eng. "Onomatopeia", "mimetic words", "echo words", “echoism”, “imitative words”; Germ. "lautmalerei”, "schallnachahmung”; Ott. "lafz-ı taklidi”, "savt-ı taklidi”; Rus. "zvukopodrazhaniye”; Tuv. "öttünüg söster” such names. There are onomatopoeic words in all world languages. In the all areas of Turkish language, there are in large quantities of onomatopoetic words. In Turkish, onomatopoeic words can be derived with verb derivational suffixes. In Tuvan Turkish, there are suffixes derive denominal verbs, such as -IrA(buzura- to sizzle); +(A)r- (dızıra- to scrunch); +LA- (siile- to blow); +rA- (şllıra- fizz); +DA- (nttta- to clatter); +A- (dogdura- to rumble); +KIlA- (dıngıla- to clank); +KAyn- (daldırtkayın- to rustle) ve +GIr(A)- (kangıra-, to tinkle). In addition, onomatopoetic words can be used with auxiliary verbs like de-, kıl-, kın- kılın- in Tuva Turkish. These auxiliary verbs indicate that a sound suddenly appears.
\end{abstract}

$1 \quad$ Dr. Öğr. Üyesi, Kırklareli Üniversitesi Fen Edebiyat Fakültesi, Çağdaș Türk Lehçeleri ve Edebiyatları Bölümü, (Kırklareli, Türkiye), ilkertosun@yandex.com.tr, ORCID ID: 00oo-0003-1428-4772 [Makale kayıt tarihi: 11.06.2019-kabul tarihi: 18.08.2019; DOI: 10.29000/rumelide.606066] 
The following examples can be given for these uses, which are called "dürgen vid" (instantaneous aspect) in Tuvan grammars: çıırt de- "make noise", dırbaş de- "be startled"; dazırt kın- "to scrunch", dıylaş kın- "to shake"; dırt kıl- "suddenly hit”, tok kıl- "to hit”; karaş kılın- "to vanish”, kıngırt kılın"to clang". In this paper, we search these auxiliary verbs, onomatopoeic words, and their functions.

Keywords: Onomatopoeia, onomatopoeic words, Tuvan Turkish, auxiliary verb.

\section{Giriş}

Yansıma sözler (Tuv. öttünüg söster) hem doğada hem de insanların gündelik yaşamlarında var olan çeşitli gürültülerden, bağırma-çă̆ırmalardan; varlıkların hareketlerinden ve insanların bedenlerinden çıkan/çıkarılan seslerden oluşan sözcüklerdir² (Sat, Salzııma 1980: 218). Hem konuşma dillerinde, hem de yazı dillerinde yansıma sözcüklere tesadüf etmek mümkündür. Hatta bazı Afrika ve Avustralya yerli dillerinde yansıma sözcükler, sayıca o kadar çoktur ki bilim adamları bu dillere "click languages" (tıngırdayan diller) adını vermiştir (Pennisi 2004: 1320), (Traunmüller 2003: 1) Öznel bir ifade ile Türk dilinin de yansıma sözcükler bakımından zengin bir dil olduğu söylenebilir. Gerek tarihî, gerek çağdaş Türk lehçelerinin söz varlı̆̆ında azımsanmayacak ölçüde yansıma sözcük bulunduğu görülmektedir.

Türk dilinde yansıma tabanlar, dilin genel karakteristiği itibariyle isimden isim ve isimden fiil yapım ekleri ile genişletilebilmekte; yansıma tabanın bildirdiği ses ile ilgili yeni isimler veya o sesi çıarmak anlamında fiiller türetilebilmektedir. Daha önceki bir çalışmamızda, Tuva Türkçesinde yansıma isim köklerinden fiil türeten +GIr(A), (kaygıra-, çıngırdamak) ekini incelemiş; bu sahada +GIr(A) ile beraber +IrA- (buzura- cızırdamak); +(A)r- (dızıra- çatırdamak); +LA- (siile- şiddetle esmek); +rA- (şlırafişırdamak); +DA- (ıtta- ses çıkarmak); +A- (dogdura- gümbürdemek); +KIlA- (dıngıla- şakırdamak); +KAyn- (daldırtkayın- hışırdayıp durmak) ekleri ile yansıma köklerden "o sesi çıkarmak, gürültü yapmak" anlamında fiiller türetilebildiğini ifade etmiştik.

Tuva Türkçesinde yansıma isimler ayrıca çeşitli yardımcı fiillerle birlikte kullanılarak, yukarıda geçen eklerin sağladığı "yansıma sesin bildirdiği sesi çıkarmak” anlamında söz öbekleri oluşturabilmektedir. Bu bildiride Tuva Türkçesinde "yansıma isim + de-/kıl- (kın-, kılın-)” yapısının işlevleri tematik olarak incelenecek, ayrıca çalışmanın sonunda Tuva Türkçesinin temel sözlüklerinden derlenen bu türden söz öbekleri alfabetik olarak verilerek araştırmacılara konuyla ilgili kıyaslama imkânı sunulacaktır.

\section{Tuva Türkçesinde de- ve kıl- (kın- / kılın-) fiilleri}

Tuva Türkçesinde söz konusu yapı aslında birer esas fiil olan de- ve kıl- (kılın-, kın-) yardımcı fiilleri ile meydana getirilmektedir. Ayrıca bu iki fiilden biri olan kıl- fiilinin dönüşlülük çatısı eki -(I)n almış biçimleri olan kılın- ve kın- $(<$ kıl-ın-ır) da yansıma sözlerle birlikte kullanılmaktadır. de- ve kılfiillerinin sözlük anlamları şöyledir:

de- (di-): 1. konuşmak, 2. isimlendirmek, ad koymak; çağırmak; telaffuz etmek, 3. denen, denilen 4. gelecek zamanda çekimlenmiş fille birlikte eylemin bildirdiği hareketi gerçekleştirme arzusu ifade eder. 5. bir cümlede yüklem olarak kullanılan geçmiş zamanın olumsuzu ile çekimlenmiş fiille birlikte, eylemin bildirdiği hareketin çok defa veya güçlü bir şekilde gerçekleştirildiğini ifade eder. 6. yansıma

2 Dilin doğuşuna ilişkin teoriler açısından anahtar bir kavram olan yansıma sözcükler, kimi zaman dillerarası (interlanguages) olarak karşımıza çıkarlar, yani aynı ses kaynağından çıkan/çıkartılan sesler, aynı şekilde ifade edilebilir. Bununla birlikte bu değişmez bir kural değildir. Bussman, bu durumu horoz ötüşü ile örneklendirmektedir: İngilizce'de horoz ötüşü anlamında cocka-doodle-doo, Almanca'da kikeriki, Fransızca'da cocorico sözcükleri ile karşlanmaktadır (Bussmann 2006: 836). 
fiillerle birlikte kullanılarak o yansıma sesi çıkarmak anlamında fiil meydana getirir (Monguş 2003: 597).

kıl-3: 1. gerçekleştirmek, yapmak, 2. hazırlamak, kaynatmak, pişirmek (yemek), 3. dikmek (elbise), 4. inşa etmek, 5. tamamlamak, bitirmek, 6. yazmak, 7. kurmak, tesis etmek, 8. herhangi bir vazife için atanmak, 9. gerçekleştirmek, yapmak; kabahat işlemek, 10. herhangi bir şey yapmak, çalışmak, 11. yazmak, kuralına uygun bir şekilde bir şey yazıp hazırlamak, 12. nesne adı ile birlikte kullanılarak bir eylemi ifade eder, 13. herhangi bir nesneyi yaparak kullanmak, 14. davranmak, tavir sergilemek, 15. konuşuvermek, soruvermek, 16. yansıma sözlerle birlikte, o yansıma sözle ilgili fiil meydana getirir. (Monguş 2011: 289).

Görüldüğü üzere bu fiiller, diğer Türk lehçelerinde olduğu gibi Tuva Türkçesinde de birden çok anlama sahiptir. de- ve kıl- yukarıda da zikredildiği gibi yansıma seslerle birlikte Tuva Türkçesinde "belirli bir ses çlkarmak" ve "belirli bir tarzda, hızda ve şekilde ani, hızlı, çabuk hareket etmek" anlamında yapılar oluşturmaktadır. Tuva Türkçesinde yansıma ses + yardımcı fiil yapısının görünümü şöyle gösterilebilir:

I. "yansıma ses + de-/kıl-/kılın-/kın-" yapısı genel olarak "belirli bir sesi çıkarmak", "gürültü yapmak" ifadesi taşımaktadır. Nitelikleri bakımından bu sesler şöyle sınıflandırılabilir:

a) Çıkarılan yansıma sesin süresini, çıkarılma sıklığını veya gücünü/zayıflğını bildirir:

> tek kerelik çıkarılan sesler: kangırt deer/kılır/kınnır "tek bir kere ses çlkarmak": Baza-la telefon kaygırt didi. "Ve telefon çınladı (çın dedi)".

> kısa süren sesler: dars deer "kısa, kesin ses çıkarmak": Kımçı baa agaarga dars deen. Kamçı havada şakladı (şak dedi).

> çok kerelik, tekrar tekrar çıkarılan sesler: dars-dars deer "tekrar tekrar ses çıkarmak": Ok deerge sayt-sıyt-daa deer, dars-dars-daa deer, baş kırı-bile sı-daa deer. Mermi dediğin cirıldar da, yankılanır da, kafanın üstünde vızıldar da.

> ansızın ses çıkarmak: dars-dirs deer "ansızın bir ses çıkarmak": Dars-dirs deen soonda, dört ool kire haljipp kelgenner. Ansızın çıkan gürültüden sonra dört oğlan içeri koşarak geldiler.

> güç duyulur ses çıkarmak: pıt deer/kılınır "bir nesne veya varlık tarafından zayıf bir ses çıkarmak": Oozu-bile dıt bajında diïni boolarga, pıt deer. Kendi başına melez ağacının yanında ateş ettiğinde pit diye bir ses duyulmuş.

> güçlü bir ses çıkarmak: kazır-kozur deer "güçlü bir ses çlkarmak, çatırdamak": Çer sirt kılıngan soonda, kazır-kozur-la deen. Yer tepe haline getirildikten sonra büyük bir çatırtı duyuldu.

b) Bir nesnenin suya ya da toprağa düşmesi sonucu çıkan sesleri bildirir:

> suya düşen bir nesnenin çıkardı̆̆ı sesler: moyt deer/kınnır "suya atılan veya suya düşen ağır bir nesne ses çıkarmak”: Kolya’nı dajı iyi-üş hire kakkaş, sugje moyt deer bolgan. Kolya’nın (attığı) taş, iki

3 kıl- fiili anlamsal çeşitlilik bakımından Tuva Türkçesi ve Türkiye Türkçesi yazı dili arasında farklılık göstermektedir. Türkiye Türkçesinde bu fiil sadece "1. etmek, yapmak; 2. namazı yerine getirmek" anlamlarını ihtiva etmektedir (Türkçe Sözlük 2005: 1154). 
üç kere sektikten sonra suya cumburlop diye düştü. möy deer / kınnır "suya düşen veya atılan bir nesne ses çıkarmak": Kezek bolgaş-la ol sugje möy digeş, bambuktu ulay sürgeş çoruptar turduvus. Bir süre sonra bambuyu itip suya cumburlop diye düşürerek geçip gittik.

> toprağa, yere düşen bir nesnenin, varlığın çıkardığı sesler: dirt-dart deer "insanın yere bastığında veya bir nesnenin yere düştüğünde çıkardığı sesi bildirir”: Dirt-dart deen soonda, nazıtı kire halıp kelgen. Yerden çıkan gürültüden sonra Nazıtı içeri sıçrayarak girdi.

c) Çıtırdama, çatırdama, gıcırdama, tıkırdama, hışırdama gibi tabiat seslerini bildirir:

> çatırdama sesleri: dazırt deer / kınnır "çatırdamak": İzig sug kutuptarga, stakan dazırt deen. Sicak su konduğunda bardak çatırdadı.

> kütürdeme sesleri: kizirt deer "kütürdemek, çatırdamak": Baraan olurgan çerinden turarga, diskekteri kizirt deen. Hayvanların yattığı yerde dururken, dirsekleri kütürdedi.

> gıcırdama sesleri: kijurt deer/ kıyırt deer "gıcırdamak": "Ejik kıyırt deen soonda, bir kiji kirip keldi. Kapı gıcırdadıktan sonra bir kişi içeri gelip girdi.

> hışırdama sesleri: kıldırt deer "hışırdamak, fikırdamak": Araganıı ajı ol be azı çüzül, a aaa aray boostaazı kıldırt didi. İçkinin acılığından mı nedir, boğazı biraz hışırdadı.

> şırıldama sesleri: koyt deer "şırıldamak, suyla ilgili sesler çıkarmak"

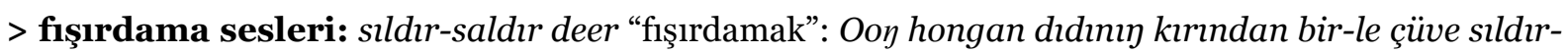
saldır daaş ündürüpkenini soonda ooy bajın bir-le çüve ulday şaapkan. Onun içine girdiği deliğin üstünden bir şey fişırdadıktan sonra başına bir şey çarptı (Darjay 2009: 47).

> tıkırdama sesleri: tok-tak deer / kılır "tıkırdamak, takırdamak": Şkolaga keerimge, aştakçılar, ot sahkçıları-la boor, ında-mında tok-tak deer daaltar üner çüve boldu. Okula geldiğimde temizlikçiler, ateş yakanlar vardı, her yerde tok-tak diye sesler duyuluyordu (Keçil-ool 2004: 230).

d) Hayvanların çıkardı̆̆ı sesleri bildirir:

> ag deer "havlamak": Ayt deer kiji çok, ag deer tt yok, a tudup çïr mal baza çok. Hey diyen kimse yok, hav diyen köpeği yok, yakalayıp yenecek hayvan yok4. dalbaş deer / kınnır "kanat çırpmak" kuş çalgınnarın dalbaş kılgan kılgan. Kuş, kanatlarını çırpmış. kargırt deer "hırıldamak": A'ttı haayı kargırt deen. At burnundan hırıldamış. sayt deer "saksağan ötmek": Taynuldar sayt deer saaskan-daa çandır kirbes çııı haragalzap turgannar. Bekçiler, neredeyse öten saksağanları bile içeri sokmayacak bir şekilde nöbet tutuyorlar. didirt deer/kılır "koşarken ayaklardan ses çlkarmak": Şuraan aynı davannarı didirt deer. Kaçan av hayvanlarının ayakları didirt diye ses çıartır.

e) Hayvanları gütmek için çıkarılan sesleri bildirir:

> ay deer "ay ay diye ses çıkartarak sürüyü bir yere sürüp düzene sokmak": Çurtta bızaalarnı ay dep ekkeliner. Obada buzağıları ay diye çağırırlar. Ayt! Ayt! Bak öşkü-dür evespe bo. (Minda ayt dep sözü kijinin öşkünü daygırganın ileredir turar). Ayt! Ayt! Kötü bir keçidir değil mi bu. (Burada ayt demek,

$4 \quad$ Tuva Türkçesinde bir kimsenin yoksulluğunu anlatan bir atasözü (üleger domak). 
insanın keçiyi gütmek için seslenmesini ifade eder), (Monguş, Dorju 2001: 148). bol-bol deer "tekeyi güderken söylenen söz”: Bol-bol deer, huna ederin öttüngeni ileredir. Bol-bol demek, teke güderken yapılan seslenme demektir.

f) İnsanların çıkardı̆̆ı sesleri bildirir:

> mış deer "burnunu çekmek": Dolzat mış-daa diveen. Dolzat burnunu bile çekmedi.

g) Araç gereçten çıkan, bunlarla çıkarılan sesleri bildirir:

> çirs deer "ateşli silahlardan ses çlkarmak": İyi urug ol-la bar çıtkaş... kazıp kaan opgar iştinçe çirsle deenner. İki çocuk oraya varıp...kazdıkları çukurun içinde ateş ettiler. çijırt deer "patlamak, gürlemek": Çijırt-la deen- ayak iyi başka bustup çaştay bergeni ol. Fincan pat diye iki parçaya ayrılıp patlayıverdi (Darjay 1991: 7). dırs-tog deer "tüfek ses çıkarmak": Aךçı kelgeş, dirs-tog kılgan. Avcı gelip ateş etti. kıngırt deer / kınnır "çınlamak". Algış-kırış kidin-ne dendep olurar üyede telefon kıngırt didi. Kavganın en yoğun olduğu zamanda telefon çınladı. sayt-sıyt deer "mermi ıslık sesi çıkarmak": $O k$ deerge sayt-sıyt-daa deer, dars-dars-daa deer, baş kırı-bile sı-daa deer. Mermi dediğin cirıldar da, yankılanır da, kafanın üstünde vızıldar da.

乌) Seslenme, çağırma bildirir:

> kıy deer "çağırmak, seslenmek, adını bağırarak söyleyerek gel demek": ... ulug ün-bile kıy deer. ...yüksek sesle seslenir.

II. "yansıma ses + de-/kıl-/kılın-/kın-" yapısı "yansıma sesleri çıkarmak" dıșında "hareket etmek" ifadesine sahiptir. Gerçekleștiren hareket genel olarak 'ani'dir. Bu yapının bildirdiği hareketin nitelikleri şöyle sinıflandırılabilir:

a) Hareketin kısa bir sürede gerçekleştiğini veya kısa sürdüğünü ifade eder:

> aazadılaş deer / kınnır "bir süreliğine açmak": Uruunuך aksı aazadılaş deen. Kızının ağzı bir süre açıldı. aazadaş kınnır "kısa bir süre açılmak": Ögnüy ejii aazadaş kılındı. Evin kapısı kısa bir süre açıldı. saadaş deer / kılınır "kısa bir süre yavaşlamak": Şapkınçı biçii-daa saadaş diveyn. Ulak hiç yavaşlamadı. alay kılır / kılınır / kınnır "kısa bir süre şaşırmak" ... alan kılbaan men. ...hiç şaşırmadım. doktaaş kınnı "kısa bir süre durmak": Novosibirsk hooraynı aeroportunga doktaaş kılgan bis. Novosibirsk şehrinin havaalanında kısa bir süre durduk.

b) Hareketin durmasin ifade eder:

> aksı hak deer "birden bire susmak": Indıg harıdan Şaajaynı aksı hak deen. Böyle bir cevaptan sonra Şaajay birden bire susuvermiş. soksaş deer / kılır "bir nesne kısa bir süre durmak": Henerten kıska üyede soksay beer. Ansızın kısa bir sürede duruvermiş.

c) Hareketin yönünü ifade eder:

> kalbaş deer / kulır / kınnır "geniş bir nesne yere düşmek; geniş bir nesne açllmak": Sayın-Mayındı çaglig e’tti daynap orda, ejik kalbaş deen. Sayın-Mayındı yağlı eti çiğnerken, kapı açıldı. ködürlüş deer / kınnır "bir nesne aniden yükselmek": Köörümge, çaygıs-daa ködürlüş deen hol çok. Baktı̆̆ımda 
yukarı kaldırılacak kol yoktu. mıyırlış deer / kınnır "yana hafifçe düşmek": Alüminyum tabak, araba çarptığında yana düşmüş. olaş deer / kınnır "zıplamak": Ojgar çerlerge traktör olaş kınnırga... Çukur yerlerde traktör ziplarken...

\section{d) Hareket eden nesnenin şeklini bildirir:}

> borbaş deer / kınnır "yuvarlak bir nesne hareket etmek": Ittıฤ kara dumçuu ınaar borbaş deer. Köpeğin kara burnu oraya yöneldi. maş deer / kınnır "geniş ve büyük bir nesnenin suya ya da yere düşmek": Sugga bir-le çüve maş deer. Suya yuvarlak bir şey düştü. soraş deer "uzun bir nesne ani hareket etmek": Kımçı uju soraş kınnırga, a’ttar ı̇ay bolgannar. Kamçı şakladığında atlar oraya gittiler.

\section{e) Bedensel hareketi ifade eder:}

> bırlaş deer "aniden sallanmak, bükülmek": Bel-kejikten al-soora tudup çorda, mıyıt çaygıs-la bırlaş digen. Mıyıt balığını belinden tuttuktan sonra sadece bir kere sallandı. doygaş deer / kınnır "başını sallamak": Kijïir-ool şala doygaş kılıngaş, ınay-beer körgüleen. Kijiir-ool, başını biraz sallayarak oraya buraya bakıp durdu. kelçeş deer "geniş aralıklarla adım atmak": Kelçeş deeş hemni kejir bastırıp... Geniş adımlar atarak nehri geçmek için...

f) Hareketin aniden, çabuk, hızhca gerçekleştiğini ifade eder:

> aartaş deer / kınnır "bir nesne aniden ağırlaşmak": Andrey turup herilgileerge, bir talakı karmanında bir-le çüve aartaş kılıngan. Andey durup ceplerini yoklarken, cebinin birinde bir şeyin ağırlı̆̆ını hissetmiş. adış deer / kınnır "aniden korkmak": Süreedeeninden kuyga-bajı adış digen. Heyecanlandığında tüyleri diken diken olmuş (aniden çok korkmuş). burt deer "aniden toz toprak yükselmek": Burt deer dovurak çok, kızıl-davan kılaştap bolur. Tozuyacak toprak yok, yalın ayak dolaşılır. doldaş deer "çok hızlı gitmek": Baştay Konçug doldaş digen. Önce Konçuk hızlandı. siliş deer / kılınır / kınnır "ani hareket etmek": Meey buttarım adaanda çer sirleş didi. Ayaklarımın altındaki yer birden hareket etti.

\section{Bu yapı aniden gelişen duygusal tepkileri ifade eder:}

> adış deer / kınnır "aniden korkmak": Süreedeeninden kuyga-bajı adış digen. Heyecanlandığında tüyleri diken diken olmuş (aniden çok korkmuş). arnı iziş deer "aniden korkmak; aniden yüzü kızarmak, utanmak": Arnım iziş digeş, atkaar hahy berdim. Yüzüm kızararak arka tarafa kaçıverim. atpaş deer / kılını / kınmı "aniden irkilmek, ürkmek; ürpermek": Ooђ çüree atpaş deen. Onun yüreği ürperivermiş. bıldaş deer "aniden ürkmek": A'dım bıldaş deen soonda, men-daa a'ttan ezinneldir çaştay berdim. Atım aniden ürkünce, ben de düşüverdim. dirijaş deer "aniden sinirlenmek": Dümen-ool dırıjaş-la deen. Dümen-ool aniden sinirleniverdi. dirt-dirt deer "kalbi çarpmak": Haspaajık’tı adın dınnap kaaş, Buyannı çüree dirtigeyni bergen. Haspaajık'ın adını duyunca Buyan'ın yüreği çarpıverdi. kılçaş deer / kılınır / kınnır "hızlıca veya kızgınca bakmak": Mençe kılçaş deeş: Çül ol? dep aytırgaş, sook kıldır kördü. Bana kızgın kızgın bakıp “O nedir?” diye sordu, soğuk soğuk baktı.

\section{Duyu organlarn ile algzlanan durumlarn ifade eder:}

> dokunma: iziş deer "aniden ısınmak, sıcaktan terlemek": Çunar-bajınga kirip keerge, iziş deer. Hamama giren terler. kadış deer "sert bir şey hissetmek": Henerten kadış-la deen. Aniden sert bir şey 
hissetti (Kuular 2009: 21). serïdeş deer / kınnır "aniden serin olmak": Hem kıdınga çedip keerge, seriideş digen. Nehrin kıyısına geldiğinde, aniden hava serinledi.

> tatma: demirziş deer / kınnır "demir kokan, pas kokan bir nesneyi tatmak": Adıg sır soondan çıpşıp sürgen, aksını çıdı bezin demirziş kınmıp çoraan ışkaş bolgan. Ayının peşinden giderken, ağzının kokusu bile pas kokuyormuş gibiydi.

> görme: agaraş deer / kınnır "beyaz renkli bir nesnenin aniden görünmesi ya da hareket etmesi”: Ballk sug kırında aragaş didi. Balık suyun kenarında beyaz bir nesne gibi görünüverdi. alaraş deer / kınnı "ala renkli bir varlık ani hareket etmek": Inçan meeø bügü ertken amıdıralım karaamga alaraş didi. O zaman bütün geçmiş hayatım gözümün önünde beliriverdi. bülereş deer / kılınır / kınnı "bir nesne ani hareket etmek": Şırgay şetter arazında bir-le çüve bülereş didi. Fidanların derinliğinde bir şey aniden hareket etti. kögereş deer / kınnır "mavi veya gri renkli bir nesnenin hızla hareket etmek": Börü DaşOvaa artçe kögereş didi. Kurt Daş-Ovaa geçidinden hızlıca geçiverdi. kuuraş deer / kınnır "gri renkli nesne ani hareket etmek”: Erestī karaanı ujunda bir çüve kuuraş digen. Eres’in gözünün önünde bir gri bir şey aniden geçivermiş.

\section{V. Şamanizm (Tuv. Ham Çüdülgezi) ve güreș (Tuv. Hüreș) terimleri oluşturur:}

Az sayıda da olsa bu yapının Şamanizm ve güreş sporu ile ilgili terimlerde kullanıldığı tanıklanmaktadır: Şamanizm (Hamnaar çoruk) alas alas deer "kötü ruhların neden olduğu hastalıkları defetmek için ardıç tütsüsü yaparken algış söylemek": Artışt kıpsıp algaş, ooy kırınga budu alastap turar, ol bolza hamnaar betinde budun arıglaarı ol. Ardıçı yakarak, alas alas diyerek bacağı tütsüledi, bu kamlık etmeden önce temizlemek demekti. Güreş (Hüreş): dükteş kılır "kolayca yenmek, sırtını yere getirmek”: Naçın möge udurlanıkçızın dükteş kılgan. Naçın pehlivan, rakibini kolayca yendi.

\section{Bu yapı ölümle ilgili örtmece sözlerde kullanılır.}

Şamanizm inancı çerçevesinde Tuva kültüründe "ölüm” ile ilgili çeşitli tabular bulunmakta, bu tabular nedeniyle "ölmek" fiili yerine çeşitli örtmeceler kullanılmaktadır. Ölümle ilgili çok sayıda örtmece arasında "yansıma ses + de- / kıl- (kılın-, kın-) yapısıyla oluşturulmuş söz öbekleri de mevcuttur: döygürgeş deer "aniden hareket etmek, aniden yok olmak; ölmek"; karaş deer / kınnr "kara bir şey görünmek; çok hızlı koşmak; ansızın ölmek; aniden üzülmek, kederlenmek”

\section{Bu yapı deyimlerde kullanılır.}

> aksı hak deer "birden bire susmak; dut yemiş bülbül gibi olmak, söyleyecek söz bulamamak": Indıg harıdan Şaajaynı aksı hak deen. Böyle bir cevaptan sonra Şaajay birden bire susuvermiş. karak çiveş deer / kınnır arazında "çok hızlı, göz açıp kapayıncaya kadar": Karak çiveş deer arazında Eres kurug çer kuspaktap algan turgan. Eres kaşla göz arasında bir avuç toprak alıvermiş. karaygılaş deer "1. Çok hızlı kararmak, sönmek; kederlenmek”: Karaktarı karaygılaş deen soonda, ezer kırında şöyüldür çıdıpkan. Gözleri karardıktan sonra, eyerin üzerine yığılıp kalmış (Darjay 2009: 50).

VIII. Bu yapr ikileme biçiminde de kurulmaktadır:

> kıyırt deer "tek bir defa gıcırdamak, çatırdamak, kütürdemek", kogjurt deer "(bir defa) çıtırdamak" örneklerinden görüldüğü gibi çıkarılan sesin tek bir defa (çangıs katap) meydana geldiği, tek bir defada 
çıkarıldığı belirtilmektedir. İkilemeli yansımalar ise yardımcı fiillerle birlikte bazı örneklerde "tekrar tekrar ses çıkarmak" ifadesine sahiptir: dars-dars deer "tekrar tekrar ses çıkarmak".

\section{Sonuç}

> Örnekler incelendiğinde bu yapıda tek heceli yansıma sözcüklerin ünsüz+ünlü+ünsüz (CVC) ya da ünsüz+ünlü+ünsüz+ünsüz (CVCC) biçiminde olduğu görülmektedir: dig deer: 1. gürlemek 2. uçuvermek 3. ürküvermek: dig: CVC; dirt deer/ kınnır / kılır: gürültüyle düşmek, ürküp kaçmak: dirt: CVCC.

> Yansıma ses + yardımcı fiil yapısı örneklerden de anlaşılabileceği gibi iki temel işleve sahiptir. Bunlardan ilki 'belirli bir sesi çlkarmak, gürültü yapmak'tır. İkincisi ise "hareket" ile ilgilidir. Tuva Türkçesi gramerlerinde yansıma ses ve yardımcı fiilden oluşan bu yapı genellikle görünüş kavramı ile ilişkilendirilerek incelenmiştir. Bilindiği üzere görünüş “eylemin anlattığı iş, oluş, edim’i konuşucunun nasıl gördüğünü belirten dilbilgisi ulamı” olarak tanımlanmakta ve görünüş, zaman ulamından ayrı bir biçimde eylemin bitmişliği, bitmemişliği, başlangıcı, gelişimi, sonucu, yinelenişi bakımından ele alınmaktadır (Vardar 2002: 105:106). Tuvalı araştırmacılar Sat ve Salzınma bu yapının hareket işlevini görünüş (Rus. vid, Tuv. şinçi) kavramı içinde karmaşık görünüşler (narın analitiktig vidter)5 kategorisinde ve anilik görünüşü (dürgen vid) başlığı altında incelemişlerdir. Araştırmacılara göre yansıma seslerle kullanılan bu yardımcı fiiler sesin veya hareketin ani, hızlı, çabuk bir biçimde çıkarıldığını ya da oluştuğunu bildirmektedir (Salzınma ve Sat 1980: 166-170). İshakov ve Pal'mbah da bu yapıyı "birleşik analitik tür biçimleri" adını verdikleri bölümde, "tamamlanmış görünüş" alt başlı̆̆ında bu yapıyı "anilik görünüşü" (мгновенний) olarak değerlendirmişlerdir. Araştırmacılara göre Tuva Türkçesinde mecazi fiil denen filler arasında anilik anlamıla kullanılan analitik bir grup bulunmakta ve bunun ilk öğesi -ş ile bitmekte; ikinci parçada ise yardımcı fiiller yer almaktadır. Bu yapının birinci kısmında yer alan -ş eki, İshakov ve Pal'mbah'a göre eylem isimleri oluşturmaktadır ve bu durum -ş/-s denkliği çerçevesinde Saha Türkçesinde de şu örneklerde görülmektedir: çohços gin"aniden çömelmek" < çohçoy- 'çömelmek'; n’llas gin- "aniden yüzünü öne doğru uzatıvermek" < n’lay"yüzünü öne doğru uzatmak"; honos gin- "aniden gerilivermek” < honoy- "gerilmek" krş. Krg.: çokçoy// Hak.: çoçay- "çömelmek” (İshakov, Pal'mbah 1961-186;409).

> Giriş bölümünde de belirtildiği gibi yansıma isimlerden fiil türetmek için Tuva Türkçesinde kullanılan eklerden birisi -ayın / -eyin, -nayın/ -neyin, -kayın/ -keyin, -gayın/ -geyin eşbiçim birimlerine sahip olan +KAyn ekidir. Tuva Türkçesi sözlükleri incelendiğinde bu eki almış yansıma seslerle "yansıma ses + yardımcı fiil” yapısına sahip kimi söz öbeklerinin arasında ifade denkliği bulunmaktadır: kıldırt deer "fikırdamak, hışırdamak = kıldırtkaynır "fikırdamak, hışırdamak". Bununla birlikte kimi örneklerde ise sesin çıkarılma sıklığı bakımından bir anlam farklılığı söz konusudur: kögjürt deer / kinnır "bir defa kütürdemek, çitırdamak" $\Leftrightarrow$ kögjürtkeynir "tekrar tekrar kütürdemek, çıtırdamak"; kıyırt deer "tek bir defa gıcırdamak, çatırdamak, kütürdemek" $\Leftrightarrow$ kıyırtkaynır "tekrar tekrar gıcırdamak, çatırdamak, kütürdemek”.

> Bu yapı muhakkak ki sadece Tuva Türkçesine özgü veya yeni bir yapı değildir. Diğer Türk lehçelerinde de «yansıma söz + yardımcı fiil» biçiminde söz grupları mevcuttur. Örneğin Türkiye Türkçesinde yazı dilinde ve ağızlarda yansıma sözlerle birlikte et-/etme-, eyle-, ol-, çıar-/çıkarma-, de-/deme/dedirtme- yardımcı fiilleri ile birlikte kullanılmaktadır: cıs et- "çocuk dilinde yakmak", ham et-» "çocuk 
dilinde mama yemek", dık de- "ses çıkarmak", dank de- "acı bir biçimde anlamak", gık dedirtme“davranmasına firsat vermemek”, pıt pıt et- "hızlı hızlı çarpmak”, dep düp de-» "düşe kalka yürümek” vb. (Zülfikar 1995: 93-95).

> Yansıma sözcükler bir dilin taşıdığı kültürün tabiatla olan etkileşimi; tabiatın sosyal hayata, inanç sistemlerine nasıl etki ettiği, bir dilin kendi coğrafyası içerisinde nasıl şekillendiği hakkında önemli veriler sunar. Ayrıca bu sözcükler çocuk dili (Tuv. çaştar sözü), çocuklarda dil edinimi gibi konularda pedagojik çıkarımlar yapabilmemize yardımcı olur. Buna ilaveten bir dilin fonetik ve morfolojik mantığı, sözcüklerin kökenleri hakkında yansıma sözcüklerin araştırmacılara söyleceği çok şey vardır. Bundan dolayı tarihî ve çağdaş Türk lehçelerinin söz varlığındaki yansıma sözcüklerin tematik olarak incelenmesi, sınıflandırılması ve gerektiğinde komşu dillerle kıyaslanması faydalı olacaktır.

\section{Yansıma sözcük+yardımcı fiil listesi}

aartaş deer/ kınnır: bir nesne aniden ağırlaşmak (Monguş I: 41).

aazadaş kınnır: kısa bir süre açılmak (Monguş I: 32).

aazadılaş deer/ kınnır: bir süreliğine açmak (Monguş I: 32).

adış deer/ kınnır: aniden korkmak (Monguş I: 71).

agaraş deer/kınnır: beyaz renkli bir nesne aniden görünmek ya da hareket etmek (Monguş I: 71).

agbaş deer / kınnır: dik tüylü bir hayvan aniden hareket etmek veya görünmek (Monguş I: 57).

ag deer: havlamak, aralıksız güçlü bir ses çıkarmak (Monguş I: 57).

ajıksış deer: acısını hemen hissetmek (Monguş I: 76).

ajış deer / kılır: yarayı deşmek; aniden ağrılı olmak (Monguş I: 82).

aksı hak deer birdenbire susmak (Monguş I: 45).

alay kılır: kısa bir süre şaşırmak (Monguş I: 105).

alaraş deer/ kınnır: ala renkli bir varlık/nesne aniden hareket etmek (Monguş I: 105).

alas alas deer: kötü şeyleri, hastalıkları uzaklaştırmak için etrafında tütsü dolaştırırken alkış (algış) söylemek (Monguş I: 106).

alçaş deer: hızlı hızlı yürümek (Monguş I: 118).

arnı iziş deer: aniden korkmak; aniden yüzü kzzarmak, utanmak (Monguş I: 167).

artılaş deer: hızlı adımlarla geçidi aşmak (Monguş I: 162).

atpaş deer: aniden irkilmek, ürkmek (Monguş I: 177).

ay deer: ay ay diye ses çıkartarak bir yere sürmek, düzene sokmak (Monguş I: 87).

ayt deer: ayt diye ses çıkartarak (hayvanları) bir yere toplamak (Monguş I: 90).

baarı ajış deer: bağrı yanmak (Monguş I: 193).

baarı halaş deer: çok merhamet etmek. bkz. baarı soolaş kılınır (Monguş I: 193).

baarı soolaş kılınır: çok acımak, merhamet etmek (Monguş I: 193).

başka çı deer: aniden akla düşünce gelmek (Monguş I: 228).

bıldaş deer: aniden ürkmek (Monguş I: 342).

bırlaş deer: aniden sallanmak, bükülmek (Monguş I: 345).

bol-bol deer: keçiyi güderken söylenen söz (Monguş I: 276).

borbaş deer/ kınnır: yuvarlak bir nesnenin ani hareket etmek (Monguş I: 291).

burt deer:1. aniden toz, toprak yükselmek. 2. hızlı koşmak (Monguş I: 316). 
büldeş deer / kınnır: gözleri yaşarmak (Monguş I: 331).

bülereş deer/ kılınır/ kınnır: bir nesne ani hareket etmek (Monguş I: 332).

çayt deer: gürültü yapmak (Tenişev 1968: 512).

çım deer: ağrımak (kalp hakkında) (Tenişev, 557).

çırgırt deer: vak vak etmek, hırıldamak (Tenişev, 558).

çık deer: çıtırdamak, çatırdamak (Tenişev, 554).

çımırt deer: sancımak (Tenişev, 557).

çırs deer: çatlamak, tıklamak (Tenişev, 558).

çirs deer: atış hakkında ses (Tenişev, 536).

çijırt deer: patlamak, gürlemek (Tenişev, 554).

dalbaş deer/ kınnır: çırpmak (kanat), (Monguş I: 384).

daldır-doldur deer: gürültü ile uçmak (Monguş I: 387).

dars deer: kısa, keskin ses çıarmak (Monguş I: 395).

dars-dars deer: tekrar tekrar ses çıkarmak (Monguş I: 395).

dars-dirs deer: ansızın ses çıkarmak, çıkan ses (Monguş I: 395).

daldırt deer: hışırdama sesi çıkarmak (Monguş I: 387).

dazırt deer/ kınnır: çatırdamak (Monguş I: 378).

demirziş deer: demir kokan, pas kokan bir nesneyi tatmak (Monguş I: 421).

dıyzış deer: bir şey kısa sürede gerçekleşmek (Monguş I: 555).

dırbaş deer: irkilmek (Monguş I: 560).

dırıjaş deer: aniden sinirlenmek (Monguş I: 562).

dırlaş deer: aniden tutuşmak (Monguş I: 561).

dırs deer: çıtırdamak (Monguş I: 561).

dırs-tog deer: tüfekten çıkan sesi gösterir (Monguş I: 454).

dırtaş deer: aniden irkilmek (Monguş I: 561).

dıylaş deer/ kınnır: sallamak, kıvrılmak (Monguş I: 550).

dızır kınnır: çatırdamak (Monguş I: 549).

dızırt deer: çatırdama sesi duyulmak (Monguş I: 549).

didirt deer: koşarken ayaklardan çıkan ses (Monguş I: 442).

dig deer: 1. gürlemek 2. uçuvermek 3. ürküvermek (Monguş I: 441).

dirs deer: çatırdamak (Monguş I: 454).

dirt deer/ kınnır / kılır: gürültüyle düşmek, ürküp kaçmak (Monguş I: 454).

dirt-dart deer: insanın yere bastığında veya bir nesnenin yere düştüğünde çıkardığı sesi bildirir (Monguş I: 454).

dirt-dirt deer: kalbi çarpmak (Monguş I: 455).

dogdur deer: katı veya donmuş bir yüzeyden ses çıkmak (Monguş I: 460).

doktaaş kınnır: kısa bir süre durmak (Monguş I: 467).

doldaş deer: çok hızlı gitmek (Monguş I: 471).

doygaş kınnır/ deer: başını sallamak (Monguş I: 477).

döygürgeş deer: aniden hareket etmek; aniden yok olmak, ölmek (Monguş I: 498).

dükteş kılır: kolayca yenmek (Monguş I: 530). 
dürt deer: çok hızlı gitmek; yok olmak (Monguş I: 542).

halaş deer / kılır: aniden inmek, sarkmak, çökmek; aniden indirmek, sarkıtmak, götürmek, başını bir kere sallamak (Tenişev, 464).

hay deer: 1. yatıştırmak, yumuşatmak. 2. nizama davet etmek, terbiyeli olmayı öğretmek (Tenişev, 461).

hoduş deer: kuyruğu dikmek (Tenişev, 478).

imireş deer: görünüp kaybolmak (Monguş I: 588).

iziş deer: aniden ssınmak (Monguş I: 582).

kadış deer: 1. sert bir şey hissetmek. 2. zokayı kapmak (Monguş II: 31).

kagjır-kagjur deer: biraz çatırdatmak (Monguş II: 18).

kajaraş deer: görünüp kaybolmak (Monguş II: 35).

kalbaş deer: yere düşmek; geniş bir nesne hareket etmek (Monguş II: 50).

kaygırt deer: tek bir kere ses çıkmak (Monguş II: 62).

karak çiveş deer / kınnır: kaşla göz arasında, çok hızlı hareket etmek (Tenişev, 228).

karaygılaş deer: 1. çok hızlı kararmak, sönmek. 2. kederlenmek (Monguş II: 77).

karaş deer/ kınnır: kara bir şey görünmek; çok çabuk koşmak, çabuk düşmek, çabuk geçmek, ansızın ölmek; aniden üzülmek, kederlenmek (Monguş II: 80).

kargırt deer: hırıltılı ses çıkarmak (Monguş II: 83).

kazır-kozur deer: güçlü bir ses çıkarmak, çatırdamak (Monguş II: 38).

kelçeş deer: geniş aralıklarla adım atmak (Monguş II: 117).

keldeş deer: bir nesne eğilmek (Monguş II: 114).

kıjırt deer: 1. gıcırdamak. 2. çıtırdamak, kütürdemek (Monguş II: 267).

kılaş deer: parlamak (Monguş II: 285).

kılçaş deer/ kılınır/ kınnır: hızlıca veya kızgınca bakmak (Monguș II: 287).

kıldırt deer: fikırdamak, hışırdamak (Monguş II: 286).

kıy deer: demirden, çandan, zilden ses çıkmak (Monguş II: 292).

kıngırt deer / kınnır: çınlamak (Monguş II: 293).

kırlaş deer: bir nesne yukarı sıçramak (Monguş II: 300).

kıy deer: çağırmak, seslenmek (Monguş II: 279).

kıymış deer/ kınnır/ kılınır: bir nesne hızlı hareket etmek (Monguş II: 282).

kıyırt deer: gıcırdamak, çatırdamak, kütürdemek (Monguş II: 283).

kızaş deer: çakmak, parıldamak, görünüp kaybolmak (şimşek hakkında), (Monguş II: 270).

kildiș deer: sarsılmak, sallanmak (Mongus II: 131).

kiy deer: ses çıkarmak, gürültü yapmak (Monguş II: 133).

kizirt deer: çatırdamak, kütürdemek, gıcırdamak, cayırdamak (Monguş II: 128).

kogjurt deer: (bir defa) çıtırdamak (Monguş II: 145).

koşkaş deer/ kınnır: aniden gevşemek (Monguş II: 185).

koyt deer: şırıldamak, suyla ilgili sesler çıkarmak (Monguş II: 153).

kozurt deer: çatırdamak, sert bir nesneden gürültü çıkmak (Monguş II: 153).

ködürlüş deer / kınnır: bir nesne aniden yükselmek (Monguş II: 193).

kögereş deer/ kınnır: mavi veya gri renkte bir nesne hızla hareket etmek (Monguş II: 190).

kögjürt kınnır: (bir defa) kütürdemek, çıtırdamak (Monguş II: 190). 
köstüş deer: bir görünüp bir kaybolmak (Monguş II: 210).

kuuraş deer/ kınnır: gri renkli bir nesne aniden hareket etmek (Monguş II: 244).

kuyga bajı adış deer: saçları diken diken olmak (Tenişev, 263).

kuyt deer: kuş ötmek (Monguş II: 222).

küspüş deer/kınnır: başını sallamak, eğilmek (Monguş II: 257).

maş deer: suya yada yere düşen geniş veya büyük bir nesne ses çlkarmak (Monguş II: 339).

maşpaş deer / kınnır: şişman veya geniş bir canlı hareket etmek (Monguş II: 340).

maytaş deer: paytak paytak yürümek (Monguş II: 325).

mee çık deer: çok soğuk olan içeceklerden biraz tatmak (Monguş II: 393).

meş deer: bkz. maş deer (Monguş II: 351).

meşpeş deer / kınnır: bkz. maşpaş deer (Monguş II: 351).

met deer: yere düşen geniş bir nesne ses çıkarmak (Monguş II: 347).

metpeş deer: bkz. maşpaş deer (Monguş II: 349).

mış deer: 1. sokuluvermek. 2. burnunu çekmek (Tenişev, 306).

mıyıraş-balbıraş deer: yalpalamak (Monguş II: 389).

mıyırlış deer / kınnır: yana hafifçe düşmek (Monguş II: 388).

mıyıs deer: yanına hafifçe düşmek (Monguş II: 387).

miş deer: 1. cup diye düşmek, küt diye düşmek. 2. burnundan gürültü ile soluk vermek (Tenişev, 296).

moçurt deer: fişkırtmak (Monguş II: 359).

moçurt-moçurt deer: fişkırtmak (Monguş II: 359).

molçurt deer/ kınnır: aniden suya düşen nesne ses çıkarmak (Monguş II: 359).

moyt deer: suya atılan veya suya düşen ağır bir nesne ses çıkarmak (Monguş II: 358).

mögeş deer/ kınnır: başın ya da beden eğilmek (Monguş II: 368).

möndüş deer / kınnır: damla damla düşmek (Monguş II: 372).

möy deer / kınnır: suya düşen veya atılan bir nesne ses çıkarmak (Monguş II: 373).

mukulduraş deer: güvercin ötmek (Monguş II: 379).

olaş deer/kınnır: zıplamak (Monguş II: 457).

opaş deer / kınnır: bir nesnenin tek bir defada yukarı yükselmek, zıplamak (Monguş II: 457).

ögbeş deer / kınnır: bir nesnenin yukarı doğru hareketini bildirir (Monguş II: 486).

ögdeş deer: yukarı aniden çıkış (Monguş II: 487).

öndeş deer: aniden yükselmek (Monguş II: 509).

öpeş deer / kınnır: bir nesne yükselmek (Monguş II: 521).

pedirt deer: 1. gürültüyle yıkılmak/çökmek.2. dolu gibi yağmak (Monguş II: 552).

saadaş deer / kılınır, kılır: kısa bir süre yavaşlamak (Monguş II: 598).

saglaş deer: kımıldanmak (Monguş II: 606).

salbaş deer: (bir defa) sallanmak (Monguş II: 623).

salbaraş deer: bkz. salbaş deer (Monguş II: 623).

seleş deer: bir nesnenin ani, hızlı hareketini gösterir (Monguş II: 664).

seriideş deer / kınnır: aniden serin olmak (Monguş II: 671).

sidirt deer: aniden hareket eden bir nesnenin çıkarttı̆̆ı sesi ifade eder; kütürtü ile koşmaya başlamak (Monguş II: 678). 
sirleş deer / kılınır / kınnır: bir nesnenin ani hareketini bildirir (Monguş II: 689).

sirt deer: çarpma sonucu çkan gürültüyü ifade eder (Monguş II: 689).

soduş deer / kınnır: yapışkan bir nesne tek bir kere hareket etmek (Monguş II: 699).

soksaş deer / kılır: bir nesne ansızın kısa bir süre için durmak (Monguş II: 701).

soraş deer: uzun bir nesne ani hareket etmek (Monguş II: 701).

oytaş deer/ kınnır: çok hızlı başını arkaya atmak (Monguş II: 431).

palt deer: aniden korkmak (Monguş II: 543).

pet deer: küt/cup diye düşmek (Monguş II: 555).

pıt deer: bir nesne veya varlık tarafindan zayıf bir ses çıkarmak (Monguş II: 580).

püş deer: tıslama sesini gösterir (Monguş II: 579).

saldır-suldur deer: hışırdamak (Monguş II: 628).

sayt deer: 1. saksağan ötmek (Monguş II: 617).

sayt-sıyt deer: merminin çıkardığı ıslık sesini ifade eder (Monguş II: 617).

sert deer: aniden irkilmek, ürkmek (Monguş II: 672).

sirt deer: (bir defa) sancimak (Monguş II: 788).

sırtılaş kınnır: çekilmek, sancımak, acımak. bkz. sırbaş (Monguş II: 790).

sıg deer: vizildamak (Monguş II: 773).

sıldır-saldır deer: hışırdamak, fişırdamak (Monguş II: 780).

sıldırt-saldırt deer: bkz. sıldır-saldır deer (Monguş II: 780).

sıyt deer: 1. ötmek. 2. vizlldamak (Monguş II: 777).

sig deer: 1. hop etmek, titremek, oynamak (yürek için). 2. kurşun gibi/çok hızlı gitmek/uçmak (Monguş II 676).

silirt deer: ani hışırtı (Monguş II: 683).

sogaş deer: 1. pineklemek.2. başını (bir defa) sallamak.3. eğilmek (Monguş II: 694).

soolaş deer / kılır: ansızın soğuk olmak (Monguş II: 714).

soyt deer: tavşan, fare gibi hayvanlar ses çlkarmak (Monguş II: 700).

süüreş deer: aniden (kulaklarını) dikmek (Monguş II: 770).

şegeley deer: (bir hayvanı) karnından vurmak (Tenişev, 569)

şimirt deer: kalbi atmak; kalbi ağrımak (Tenişev, 574).

tırtılaş kınnır: irkilmek, çekilmek (Tenişev, 431)

tog deer: duyulmak (silah sesi için), (Tenişev, 414).

tok deer / kulır: 1. vurmak. 2. bir nefeste dikmek, bir dikişte içmek (Tenişev, 414).

tök deer: küt diye düşmek (Tenişev, 418).

üvüreş kalır: bir şeyi kaşla göz arasında yapmak, bir şeyi çok hızlı yapmak (Tenişev, 443).

\section{Kisaltmalar}

Alm. Almanca

C. Consonant (Ünsüz)

İng. İngilizce

Osm. Osmanlı Türkçesi

Rus. Rusça 
Tuv. Tuva Türkçesi

V. Vowel, (Ünlü)

\section{Taranan eserler}

Arıkoğlu, E., Kuular, K. (2003), Tuva Türkçesi Sözlüğü, Ankara, TDK.

Darjay, A. (1991), Çetker Çetkizi, Toojular, Çeçen Çugaalar, Köjegeler, Demdegdelder, Kızıl, Tıvanı Nom Ündürer Çeri.

Darjay, A. (2009), Sagıştı’ Istap Aarır Ereezi, Toojular, Kızıl, Tıvanın Yu. Ş. Kyunzegeş Attıg Nom Ündürer Çeri.

Keçil-ool, E. D. (2004), Ekii Hünüm, Şülükter, Çeçen Çugaalar, Oçulgalar, Kızıl, Tıvanın Nom Ündürer Çeri.

Kuular, Ç. (2009), “Şoraan”, Ulug-Hem, Tıva Çogaalçılarnı̀ Setküülü, No 3 (55), Kızıl, Tıvanıı Nom Ündürer Çeri

Monguş, D. A.; DORJU, K. B. (2001), Tıva Dıl, Ortumak Şkolanın 6-7 Klastarınga Ööredilge Nomu, Kızl, Tivanın Nom Ündürer Çeri.

Monguş, D. A. (2003), Tıva Dıldın Tayılbırlıg Slovarı, C. I, Novosibirsk, Nauka

Monguş, D. A. (2011), Tıva Dıldın Tayılbırlıg Slovarı, C. II, Novosibirsk, Nauka

Tenişev, E. R. (1968), Tuvinsko-Russkiy Slovar, Moskva, İzdatel'stvo, Sovyetskaya Ensiklopediya

\section{Kaynakça}

Bussman, H. (2006), Routledge Dictionary of Language and Linguistics, London, Routledge.

İmer, K. vd. (2011), Dilbilim Sözlüğü, İstanbul, Boğaziçi Üniversitesi.

İshakov F. G. , Pal'mbah, A. A. (1961), Grammatika Tuvinskogo Yazıka, Fonetika i Morfologiya, Moskva.

Karaağaç, Günay (2013), Dil Bilimi Terimleri Sözlüğü, Ankara, TDK.

Pennisi, E. (2004), “The First Language?”, Evulotion of Language, Science, Vol. 333.

Sat, Ş. Ç.; Salzınma E. B. (1980), Amgı Tıva Literaturalıg Dıl, Kızıl.

Tosun, İ. (2017), “Tuva Türkçesinde \{+GIr(A)-\} Eki”, TÜRÜK, Yıl 5, Sayl 11, ss. 509-519.

Traunmuller, H. (2003), "Clicks and the idea of a Human Protolanguage", Umea University, Department of Philosophy and Linguistics, PHONUM 9, s.1-4.

Türkçe Sözlük (2005). Ankara, TDK.

Vardar B. (2002), Dilbilim Terimleri Sözlüğü, İstanbul, Multilingual Yabancı Dil

Zülfikar, H. (1995), Türkçede Ses Yansımalı Kelimeler, Ankara, TDK. 